\title{
Determination of Viscosity Versus Pressure by Means of a Clearance Seal
}

Christiansen, Peter; Schmidt Hansen, Niels; Lund, Martin Thomas Overdahl; Spangenberg, Jon; Bay, Niels Oluf

Published in:

Journal of Tribology

Link to article, DOI:

$10.1115 / 1.4038579$

Publication date:

2018

Document Version

Peer reviewed version

Link back to DTU Orbit

Citation (APA):

Christiansen, P., Schmidt Hansen, N., Lund, M. T. O., Spangenberg, J., \& Bay, N. O. (2018). Determination of Viscosity Versus Pressure by Means of a Clearance Seal. Journal of Tribology, 140(3), [TRIB-17-1253]. https://doi.org/10.1115/1.4038579

\section{General rights}

Copyright and moral rights for the publications made accessible in the public portal are retained by the authors and/or other copyright owners and it is a condition of accessing publications that users recognise and abide by the legal requirements associated with these rights.

- Users may download and print one copy of any publication from the public portal for the purpose of private study or research.

- You may not further distribute the material or use it for any profit-making activity or commercial gain

- You may freely distribute the URL identifying the publication in the public portal 


\title{
Determination of viscosity versus pressure by means of a clearance seal
}

Peter Christiansen ${ }^{1 *}$, Niels Schmidt Hansen ${ }^{1}$, Martin Thomas Overdahl Lund ${ }^{1}$, Jon Spangenberg ${ }^{1}$ and Niels Bay ${ }^{1}$

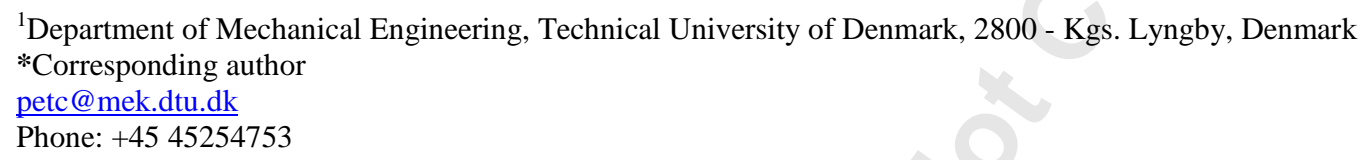

\begin{abstract}
This paper describes the construction and testing of a simple, experimental tool setup that enables determination of the pressure-viscosity relationship for high viscosity oils. Comparing the determined pressure-viscosity relationship with a reference rheometer measuring the viscosity at ambient pressure yields reasonable agreement. The computed viscosity at elevated pressures where well represented by the Chu and Cameron model.
\end{abstract}

\section{Keywords}

Lubricants, viscosity, pressure-viscosity relationship, clearance seal, Poiseuille flow

Paper number: TRIB-17-1253. Corresponding author: Christiansen. 


\section{Introduction}

The pioneering article of Reynolds [1] showed the importance of oil viscosity in lubrication of bearings. Determination of the lubricant viscosity is also required for calculations of film thickness in gears (Hamrock et al. [2]) or micro-plasto-hydrodynamic pressure build up in metal forming (Üstünyagiz et al. [3]). For the mentioned examples, the viscosity should be determined at elevated pressures.

Several experimental techniques are available for measurement of the pressure-viscosity relationship. Bridgman [4] introduced the falling body viscometer, where a body is falling inside a pressurized column of liquid and the drag force is related to the viscosity of the fluid. The mathematical foundation for computing the viscosity was improved by Irving and Barlow [5]. Bair and Winer [6] developed the technique of detecting the falling body through a non-magnetic pressure vessel of glass so that the experiment could be visually observed.

Bridgman [7] performed pressure-viscosity measurements of 43 different oils and found that viscosity was increasing with pressure. He suggested a linear relationship until pressures of approximately 100MPa

Paper number: TRIB-17-1253. Corresponding author: Christiansen. 


$$
\eta_{p}=a p+\eta_{o}
$$

where $\eta_{p}$ is the viscosity at the pressure $p, \eta_{o}$ is the viscosity at zero pressure and $a$ is a constant. At larger pressures, Bridgman reported a more rapid increase in viscosity than the linear one.

Barus [8] suggested an exponentially increasing viscosity with pressure

$$
\eta_{p}=\eta_{o} \exp (\alpha p)
$$

where $\alpha$ is the pressure-viscosity coefficient.

Chu and Cameron [9] suggested a power law type relationship

$$
\eta_{p}=\eta_{o}(1+C p)^{n}
$$

where $C$ and $n$ are constants.

One drawback of measuring the pressure-viscosity relationship is the necessity of investing in dedicated equipment such as a rheometer with a pressure module. If requirements to accuracy are less important and there is no access to such equipment, a simpler 
experimental measurement may be of interest. One such method was described in Kamal [10], who proposed to determine the pressure-viscosity relation by measuring the leakage flow through a clearance seal. He did, however, not perform an experimental verification of the method. The aim of this paper is to describe the manufacturing and use of an apparatus based on Kamal's idea whereby approximate values of the pressure-viscosity relationship can be obtained.

\section{Theory}

The experimental setup emulates a plane Poiseuille flow in a channel between stationary, parallel plates of length L, see Fig. 1.

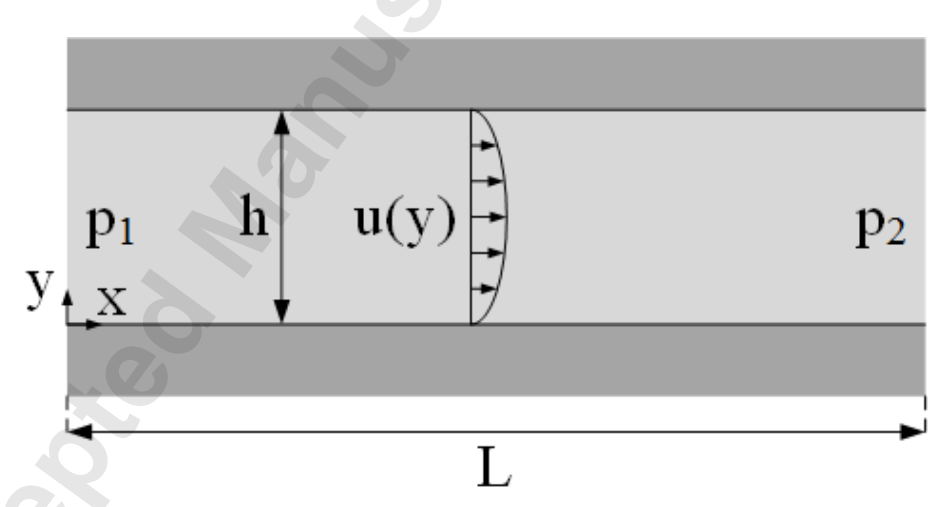

Fig. 1. Plane Poiseuille flow

Paper number: TRIB-17-1253. Corresponding author: Christiansen. 
The vertical distance between the plates is $\mathrm{h}<<\mathrm{L}$. The inlet pressure is $\mathrm{p}_{1}$ and the outlet pressure is $\mathrm{p}_{2}$. According to Kundu et al. [11] the volume flow rate $\dot{Q}$ can be computed by

$$
\dot{Q}=-w \frac{1}{12 \eta_{p}} \frac{\Delta p}{\Delta x} h^{3}
$$

where $\eta_{p}$ is the average viscosity in the channel and a linear pressure drop over the channel has been assumed.

Isolating for the viscosity yields

$$
\eta_{\mathrm{p}}=-\mathrm{w} \frac{1}{12 \dot{\mathrm{Q}}} \frac{\Delta \mathrm{p}}{\Delta \mathrm{x}} \mathrm{h}^{3}
$$

The next section describes the experimental layout and how the different quantities in Eq. (5) are determined.

\section{Experimental layout and procedure}

A test tool setup is manufactured in steel S355. The overall dimensions and setup can be seen in Fig. 2.

Paper number: TRIB-17-1253. Corresponding author: Christiansen. 


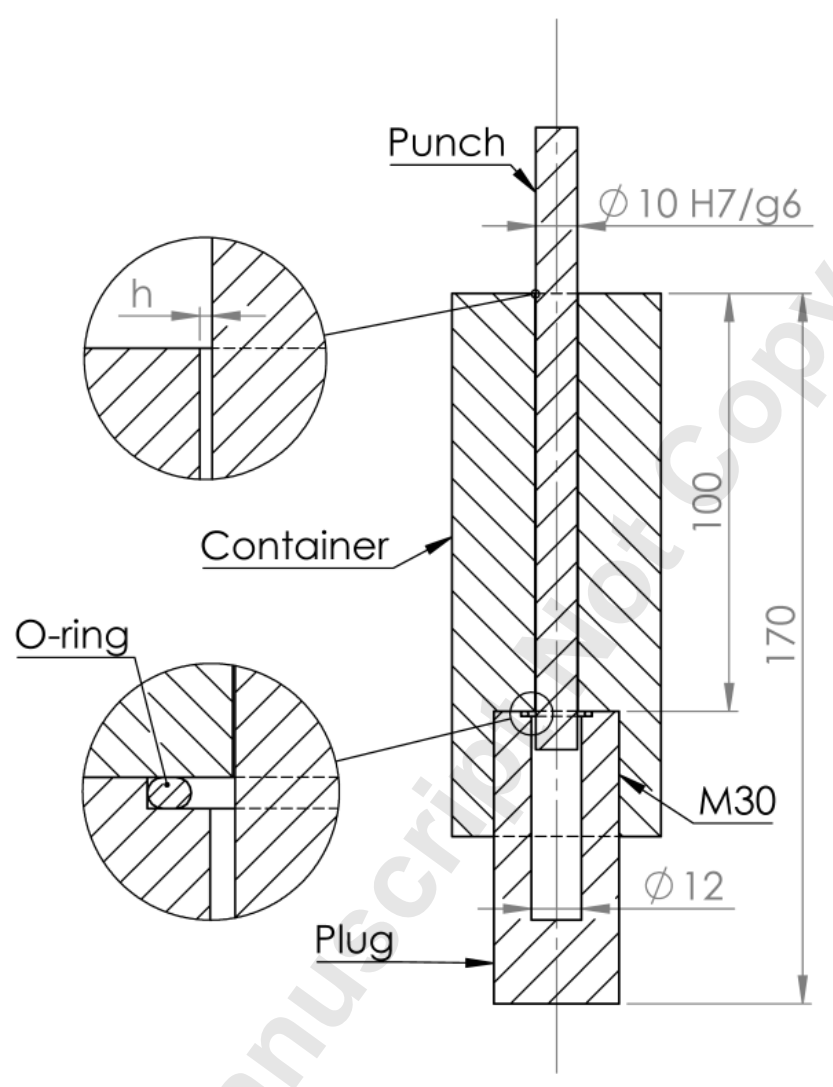

Fig. 2. Experimental tool setup

It consists of a movable punch inserted into a container with an internal bore. At the bottom end of the container, a plug is mounted with an M30 thread. The plug has an internal reservoir into which oil is filled before assembly. The reservoir, which has a larger bore than the container, is sealed from leakage between the plug and the container by means of 
an O-ring. The punch is long enough to ensure that it sticks out through both ends of the container during the whole test. This implies that the length of the clearance between punch and container is constant $(100 \mathrm{~mm})$ regardless of the exact position of the punch. The punch is free to move in radial direction and therefore assumed to be self-aligning in radial direction.

The oil can, however, leak through the small clearance between the punch and the container bore, which was machined by reaming for greater accuracy.

After assembly, the tool setup is mounted in a hydraulic press to perform the test pressing the punch into the fluid reservoir thereby causing leakage through the gap between punch and bore. By applying different press loads, varying pressures in the plug reservoir can be achieved. During testing, the punch stroke and the load is recorded in order to determine the volume flow and pressure. The data are recorded by a purpose made LabView program. The data logging frequency is $100 \mathrm{~Hz}$.

The tool setup is enclosed in a steel tube during experiments for safety reasons in case of fracture of the steel parts.

\section{Experimental data and data treatment}

Houghton CR5 (plain mineral oil) is utilized in the experiment. 
An example of a recorded data set can be seen in Fig. 3(a)-(b). Since oils are compressible [12] the volume flow rate $\dot{Q}$ is only computed when the load is held constant. These parts of the curve are marked by stars in Fig. 3(a)-(b).

The geometry of the punch and the hole where measured using a Zeiss OMC850 tactile coordinate measuring machine at $10 \mathrm{~mm}$ intervals from one end to another.

The average punch diameter was $\varnothing 9.98 \mathrm{~mm}$, whereas the average bore diameter was $\varnothing 10.02 \mathrm{~mm}$. This implies that the radial clearance $h=(10.02-9.98) / 2=0.02 \mathrm{~mm}$.

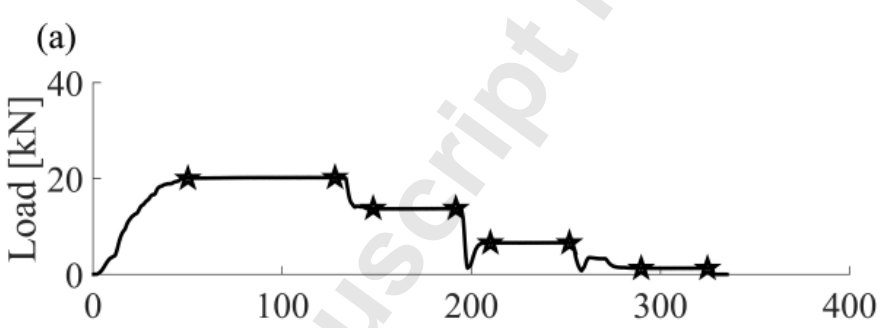

(b)

Time $[\mathrm{s}]$

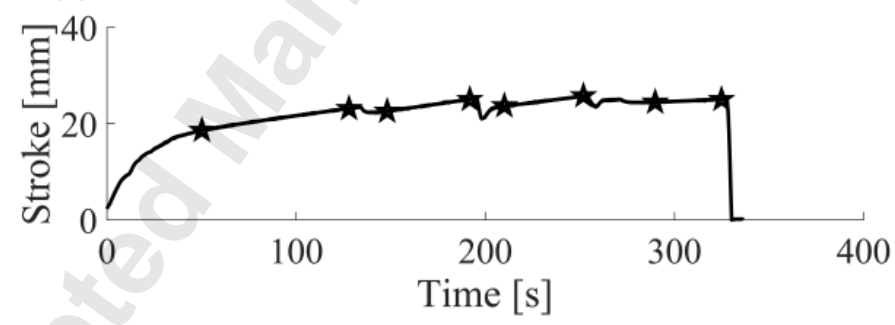

Fig. 3. Recorded time-load(a) and time-stroke(b). The stars indicate parts of the curve with constant load

Paper number: TRIB-17-1253. Corresponding author: Christiansen. 
The width $w$ of the channel is computed as the mean value of the punch and the bore perimeter. Elastic deformations of the metal parts are assumed negligible.

An average of five surface roughness measurements on punch as well as bore yielded Ra,punch $=0,547 \mu \mathrm{m}$ and Ra,bore $=1,747 \mu \mathrm{m}$.

The pressure $\mathrm{p}_{1}$ (see Fig. 1 ) is computed as the load divided by the punch cross sectional area assuming no friction between punch and container. The outlet pressure $\mathrm{p}_{2}$ in Fig. 1 is assumed to be zero, which implies that the pressure gradient $\Delta p / \Delta x=-p_{1} / L$.

The volume flow rate is determined as the punch cross sectional area times the punch velocity, which is the slope of the curve in Fig. 3(b).

Assuming a mean pressure $\mathrm{p}_{1} / 2$ in the clearance seal, the viscosity is determined as function of the mean pressure, see Fig. 4. The equations of Barus and Chu \& Cameron have both been fitted to the experimental data.

Paper number: TRIB-17-1253. Corresponding author: Christiansen. 


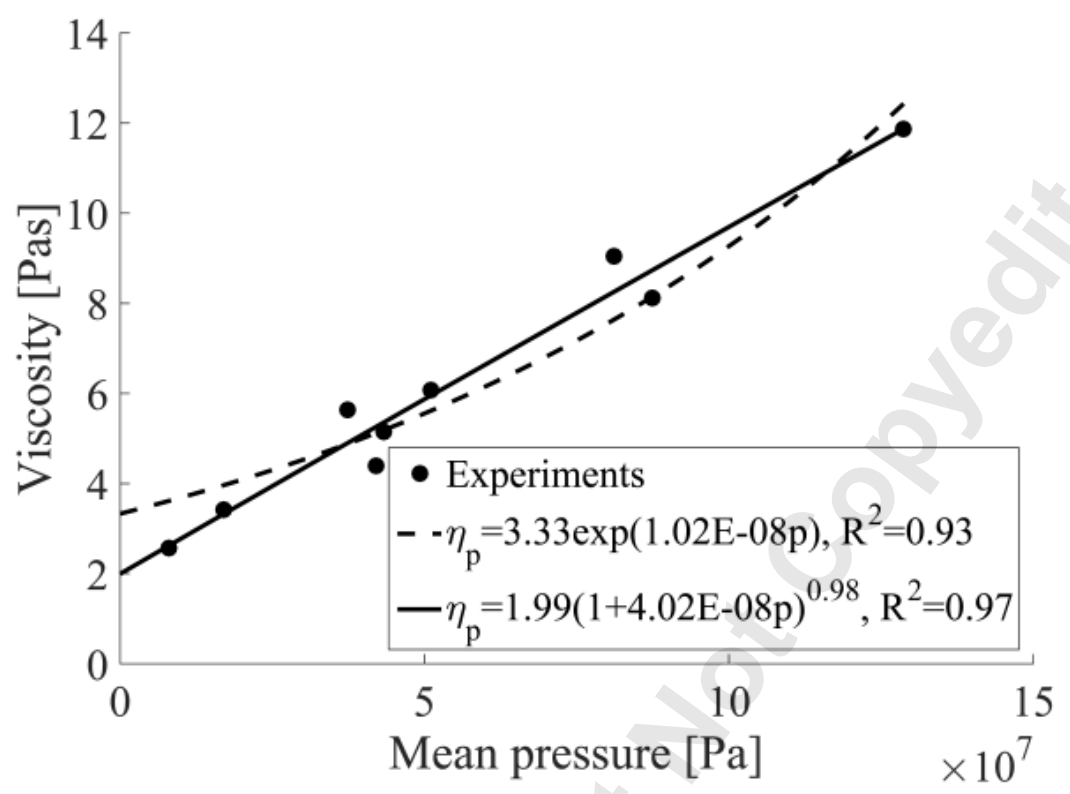

Fig. 4. Experimentally determined pressure-viscosity relationship fitted with two models and their coefficients of determination $\mathbf{R}^{2}$

Due to the slow punch speed it is assumed that shear rate effects on the viscosity are negligible and the assumption of stationary plates reasonably fulfilled.

\section{Discussion}

From Fig. 4 it can be seen that the pressure-viscosity relationship is approximately linear for the pressure interval investigated. This is in agreement with Bridgmans [7] 
observations. It has been attempted to distribute the mean pressures reasonably evenly over the entire pressure interval $0-150 \mathrm{MPa}$ to cover the pressure range.

In order to validate the experimental technique, the viscosity of the oil was measured on a reference viscometer Anton Paar MCR 502 rheometer at $25^{\circ} \mathrm{C}$, which is comparable to the temperature in the workshop during the experiments. This is important for the comparison since the viscosity is dependent on the temperature (Crouch and Cameron [13]). The resulting viscosity, as function of shear strain rate, can be seen in Fig. 5.

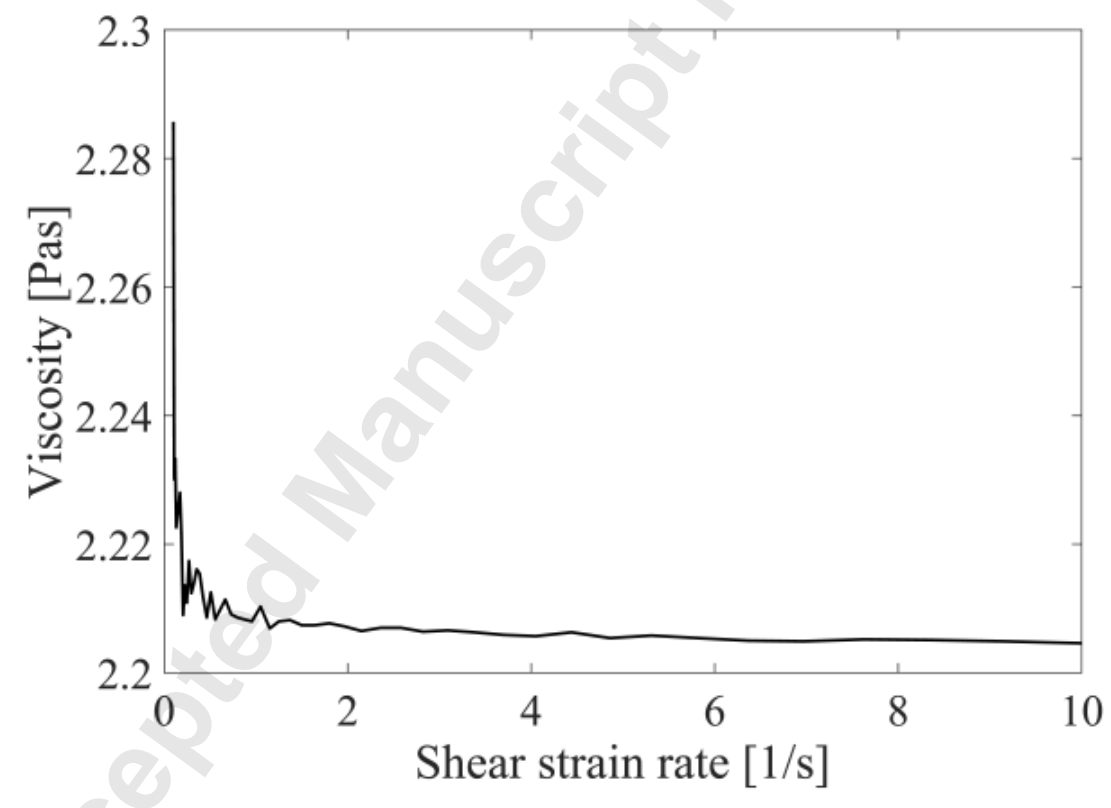

Fig. 5. Viscosity, as function of shear strain rate, at $25^{\circ} \mathrm{C}$

Paper number: TRIB-17-1253. Corresponding author: Christiansen. 
It can be seen from Fig. 5 that the oil is approximately newtonian at $25^{\circ} \mathrm{C}$ and atmospheric pressure with a viscosity of 2.21 Pas. This value is in good agreement with the 1.99 Pas predicted by the Chu \& Cameron fitted model at zero pressure, see Fig. 4, whereas the Barus equation shows poor agreement.

The reference rheometer did not allow increase of the pressure for further comparison. It should be noticed that the proposed methodology for determining the viscosity at higher pressures is only suitable for oils having a fairly large viscosity. It was attempted to perform the experiment with low viscosity oil, but the leakage flow was so large that too few data points could be recorded before the punch reached the bottom of the reservoir. This is in agreement with the hyperbolic relationship between volume flow and viscosity shown in Eq. (4).

A further expansion of the experimental equipment could be to build-in a manometer with access to the internal reservoir, thereby measuring the pressure inside the oil directly.

\section{Conclusion}

Based on the proposed idea by Kamal [10] to determine viscosity versus pressure by measuring the leakage rate in a clearance seal, an experimental tool setup has been build and tested in practice. The viscosity of a high viscous mineral oil was found to increase

Paper number: TRIB-17-1253. Corresponding author: Christiansen. 
linearly with pressure. This is in agreement with measurements by Bridgman [7]. The extrapolated viscosity at zero pressure is in good agreement with the experimentally measured viscosity obtained on a reference rheometer.

\section{Funding}

The authors would like to acknowledge the support provided by The Danish Council for Independent Research under the grant number DFF - 4005-00130 and 4005-00381.

\section{References}

[1] Reynolds, O., 1886, "On the Theory of Lubrication and Its Application to Mr. Beauchamp Tower's Experiments, Including an Experimental Determination of the Viscosity of Olive Oil,” Phil Trans R Soc Lond., 177, pp. 157-234.

[2] Hamrock, B.J., Schmid, S.R. and Jacobson B.O., 2004, Fundamentals of Fluid Film Lubrication, 2nd ed. New York: Marcel Dekker Inc., pp. 693.

[3] Üstünyagiz, E., Christiansen, P., Nielsen, C.V., Bay, N. and Martins, P.A.F., 2016, “A Fully-Coupled Approach for Modelling Plastic Deformation and Liquid Lubrication in Metal Forming”. Proceedings of the 7th ICTMP, Phuket, Thailand, 28 February-2 March 2016, pp. 45-56.

Paper number: TRIB-17-1253. Corresponding author: Christiansen. 
[4] Bridgman, P.W., 1931, The Physics of High Pressure. $1^{\text {st }}$ ed. New York: Dover, pp. 330-340.

[5] Irving, J.B. and Barlow, A.J., 1971, “An Automatic High Pressure Viscometer,” J Phys E, 4, pp. 232-236.

[6] Bair, S. and Winer, W.O., 1980, "Some observations on the relationship between lubricant mechanical and dielectric transitions under pressure,” J Lubric Tech, 102(2), pp. 229-234.

[7] Bridgman, P.W., 1925, “The viscosity of liquids under pressure,” Proc Natl Acad Sci, 11(10), pp. 603-606.

[8] Barus, C., 1893, “Isotherms, Isopiestics and Isometrics Relative to Viscosity,” Am J Sci, 45, pp. 87-96.

[9] Chu, P.S.Y. and Cameron, A., 1962, "Pressure viscosity characteristics of lubricating oils,” J Inst Petrol, 48(5), pp. 147-150.

[10] Kamal, M.M., 1968, “A high pressure clearance seal,” J Lubric Tech, 90(2), pp. 412416.

[11] Kundu, P.K., Cohen, I.M. and Dowling, D.R., 2012, Fluid Mechanics. $5^{\text {th }}$ ed. Oxford, Elsevier, pp. 313-314.

Paper number: TRIB-17-1253. Corresponding author: Christiansen. 
[12] Jacobson, B.O., 2006, “High-pressure chamber measurements,” J Eng Tribol, 220, pp. 199-206.

[13] Crouch, R.F. and Cameron, A., 1961, "Viscosity-Temperature Equations for Lubricants,” J Inst Pet, 47, pp. 307-313. 
List of figure captions

Fig. 1. Plane Poiseuille flow

Fig. 2. Experimental tool setup

Fig. 3. Recorded time-load(a) and time-stroke(b). The stars indicate parts of the curve with constant load

Fig. 4. Experimentally determined pressure-viscosity relationship fitted with two models and their coefficients of determination $R^{2}$

Fig. 5. Viscosity, as function of shear strain rate, at $25^{\circ} \mathrm{C}$ 